\title{
De erectieprothese voor de behandeling van erectiele disfunctie: herintroductie in Nederland
}

\author{
Brechje Ronkes ${ }^{1}$ A Afina S. Glas ${ }^{2}$ \\ Published online: 5 November 2018 \\ (c) The Author(s) 2018
}

\section{Samenvatting}

$\mathrm{Na}$ een periode van ruim 40 jaar heeft de erectieprothese een definitieve plaats verworven in de behandeling van erectiele disfunctie (ED) in Nederland. De erectieprothese is de laatste stap in de behandeling van ED. De voornaamste uitkomstmaat is de tevredenheid van de man. Een belangrijke negatieve factor op de tevredenheid is de postoperatieve penislengte. Door de oorzaak en de duur van de ED is deze door fibrose van de corpora meestal verkort. Ook is er in principe geen lengtetoename van de penis mogelijk bij oppompen van de prothese. Een belangrijke positieve factor voor de tevredenheid van de behandeling is een betrokken partner. Een uitdaging is - behalve de medische indicatiestelling - de psychoseksuele en relationele counseling en het managen van verwachtingen. Dit vraagt om samenwerking met een seksuoloog. Bij het falen van conservatieve therapie bij ED is het belangrijk de patiënt vlot te verwijzen naar een prothesecentrum.

Trefwoorden erectiele disfunctie $\cdot$ erectieprothese $\cdot$ penisprothese $\cdot$ hydraulische prothese $\cdot$ semirigide prothese

\section{The penile prosthesis for severe erectile dysfunction: re-introduction in the Netherlands}

\begin{abstract}
After 40 years the penile prostheses is now a well accepted treatment for erectile dysfunction (ED) in the Netherlands. The most important treatment outcome is patient satisfaction. Penile length is an important aspect of satisfaction. Fibrosis of the corpora due to the cause of ED, former treatments and the duration of ED shortens the penis. Also the penis doesn't increase in length when using the prosthesis. An involved partner has a positive effect on patient satisfaction. The challenge is to counsel the patient and partner on all medical, psychosexual and relational factors. Therefore it is a necessity to work together with sexologists. It is important when conservative therapy fails to refer a patient with ED to a centre for penile implant surgery.
\end{abstract}

Keywords Inflatable penile prosthesis $\cdot$ Erectile dysfunction $\cdot$ Malleable penile prosthesis

\section{Introductie}

In Nederland kent de erectieprothese een historie van vallen en opstaan. Udo Jonas was vermoedelijk de eerste die rond 1982 in Leiden een kunststof semirigide prothese implanteerde. Niet veel later werd de techniek opgepakt in Nij-

dr. Afina S. Glas

glas.a@zaansmc.nl

1 afdeling Urologie, AmsterdamUMC, locatie VUmc, Amsterdam, Nederland

2 afdeling Urologie, Zaans Medisch Centrum, Zaandam, Nederland megen en Rotterdam. In het kader van een door de Nederlandse Organisatie voor Wetenschappelijk Onderzoek 'ontwikkelingsgeneeskunde'-project, werd in 1985 het toenmalige Radboud Ziekenhuis aangemerkt als centrum voor implantatie van erectieprotheses [1]. Met de komst van Eric Meuleman naar het Radboudumc kwam het implanteren in een stroomversnelling terecht. Inmiddels was de hydraulische prothese op de markt gebracht, eerst door Bradley Scott (nu: AMS-prothese van Boston Scientific) en later ook door de firma Mentor (nu: Coloplast) [2]. Mentor, die voet aan de grond wilde krijgen, bood daarom de prothese aan voor een gunstige prijs. Begin jaren negentig was de subsidiebron echter opgedroogd en moest de prothese gefinancierd worden uit het eigen budget, afhankelijk van 
de lumpsum en later van het met de zorgverzekeraar afgesproken plafond. Het feest was voorbij. Vanaf die tijd werden jaarlijks per uroloog nog hooguit 5-10 van de relatief dure protheses geïmplanteerd in de ondertussen vijftien centra. Het doek leek definitief te vallen toen er eind 2013 een aanspraakbeperking op de verrichting 'implantatie penisprothese' kwam. Daarmee viel de behandeling uit het basispakket. In 2014 sloegen op initiatief van René Kropman de implanteurs de handen ineen. Zij startten een dialoog met het Zorginstituut en ontwikkelden, onder aanvoering van Marij Dinkelman en Afina Glas, een standpunt voor de erectieprothese [3]. Het Zorginstituut heeft toen in augustus 2016 besloten de aanspraakbeperking te veranderen en, onder voorwaarden, de verrichting 'implantatie penisprothese' te vergoeden. Een voorwaarde was dat er per opleidingsregio één centrum voor werd aangewezen. Thans zijn dit: Erasmus MC, UMC-Groningen, Radboudumc, St. Antonius Ziekenhuis, LUMC, Maxima Medisch Centrum en Zaans Medisch Centrum (in samenwerking met Amsterdam UMC). Een andere voorwaarde was dat er een registratie werd gestart met de uitkomsten van alle geïmplanteerde patiënten. Jarenlang ploeteren met budgetten en indicaties heeft uiteindelijk geleid tot verzekerde zorg, een duidelijke richtlijn en regionalisatie, met als ultieme doel toegankelijke zorg en een continue verbetering van de uitkomsten voor de patiënt en zijn partner.

\section{De erectieprothese}

De erectieprothese heeft als primaire doel te komen tot herstel van de erectiefunctie en secundair daaraan, een verbetering van seksueel en emotioneel welbevinden [1]. Het is een hulpmiddel dat in het lichaam wordt geïmplanteerd. Er bestaan grofweg twee soorten protheses: een manueel oppompbare hydraulische prothese (fig. 1) en een semirigide prothese (fig. 2).

Het hydraulische systeem wordt het vaakst geïmplanteerd. Het bestaat uit drie delen: een paar oppompbare cilinders, een reservoir en een pompje, die onderling verbonden zijn met de zogenaamde tubing. Het grote voordeel van de hydraulische prothese ten opzichte van de semirigide prothese is dat de penis niet voortdurend in erectie is en de erectiefunctie dus het best benaderd [1]. Plaatsing van de prothese gebeurt via een penoscrotale, een infrapubische of een subcoronaire incisie.

De bekendste driedelige protheses zijn de Titan-serie (Coloplast) en de AMS 700 ${ }^{\mathrm{TM}}$-serie (Boston Scientific). De $\operatorname{Titan}^{\circledR}$ is een Bioflex-prothese met een hydrofiele coating voor impregnatie van een antibioticum naar keuze. De AMS $700^{\mathrm{TM}}$ heeft een met antibiotica geïmpregneerde siliconen coating, de inhibizone (monocycline en rifampicine).

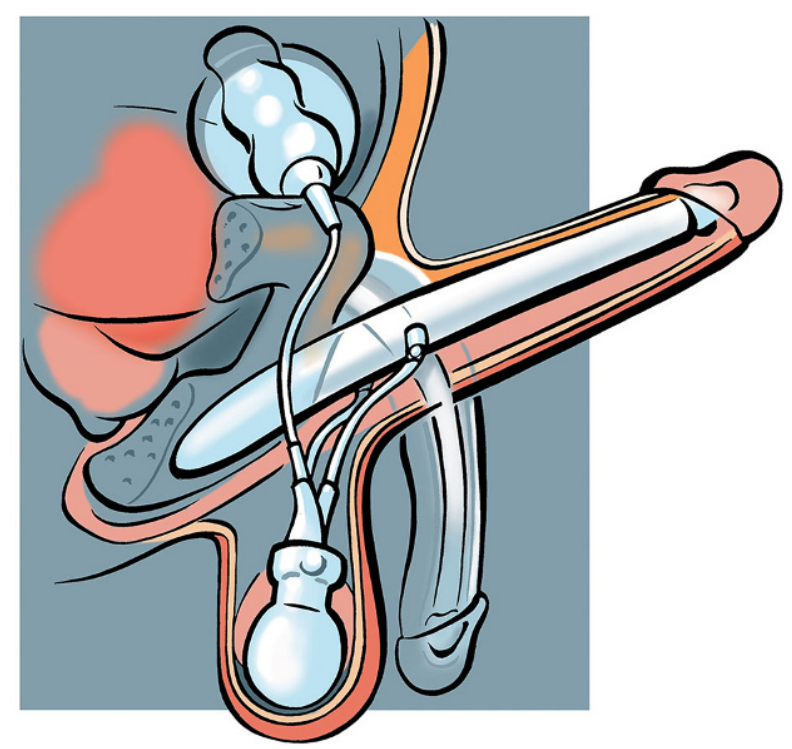

Figuur 1 Hydraulische prothese driedelig systeem (rechten: A.S. Glas)

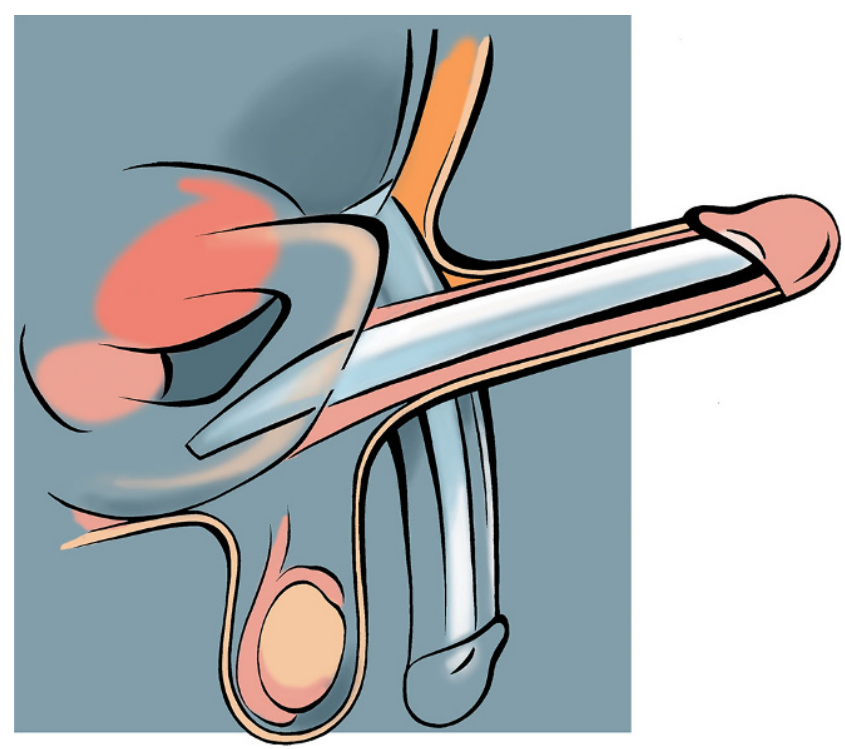

Figuur 2 Semirigide prothese (rechten: A.S. Glas)

De lengte van de cilinders wordt peroperatief bepaald. Zowel de AMS $700^{\mathrm{TM}}$ als de Titan ${ }^{\circledR}$ is er in verschillende lengtematen, die kunnen worden gefinetuned met opzetstukjes, de rear tip extenders (RTE's). De maximale diameter van de AMS $700^{\mathrm{TM}}$ is gefixeerd op $18 \mathrm{~mm}$ per cilinder. De Titan ${ }^{\circledR}$ heeft een diameter die afhankelijk is van de lengte en de mate van vulling en is maximaal $21-22 \mathrm{~mm}$. Als de corpora sterk zijn gefibroseerd, kan voor een smallere variant gekozen worden. Het reservoir wordt meestal retropubisch geplaatst via dezelfde incisie. Er is een tendens om het reservoir in de subrectus te plaatsen, wat de kans op complicaties vermindert, denk aan perforatie van blaas of darm [4]. Nadeel van deze locatie is echter dat het reservoir bij slanke mannen voelbaar en soms ook zichtbaar 
is [4]. Het Titan ${ }^{\circledR}$-reservoir is klaverbladvormig en geschikt voor zowel subrectale als retropubische plaatsing. Het AMS $700^{\mathrm{TM}}$-reservoir is rond of plat (Conceal), waarbij de laatste geschikt is voor subrectale plaatsing. In het scrotum wordt een pompje geplaatst, waar het niet opvalt, handig kan worden bediend en geen problemen geeft bij bijvoorbeeld fietsen. De cilinders vullen zich door in het vloeistofbalgje van het pompje te knijpen. Boven het balgje zit een knopje om de cilinders weer leeg te laten lopen. Oppompen van de prothese maakt de penis niet langer, uitgezonderd de AMS $700^{\mathrm{TM}}$ type LGX, die voor enige verlenging zorgt, maar dit type is niet voor alle mannen geschikt [5].

Het meest simpel te implanteren is de semirigide prothese. Bij deze prothese is de penis altijd stijf, maar wel buigbaar naar de gewenste stand. Het voortdurend rigide zijn is een nadeel. Het voordeel is dat deze prothese kan worden gebruikt door mannen met een minder goede handfunctie. Door de prijs (ongeveer $30 \%$ van een hydraulische prothese) wordt deze prothese vaak gebruikt als tijdelijke oplossing, zie verderop. In Nederland worden overwegend twee merken gebruikt. De Genesis ${ }^{\circledR}$ (Coloplast) en de Spec$\operatorname{tra}^{\mathrm{TM}}$ (Boston Scientific). De Genesis ${ }^{\circledR}$ bestaat uit een paar siliconen staven die elk verstevigd zijn met twee spiraalvormige zilverdraden en omgeven zijn door een hydrofiele coating voor impregnatie met antibiotica. De Spectra ${ }^{\mathrm{TM}}$ zijn twee staven die bestaan uit een groot aantal scharnierende segmenten van polymeer en metaal, met daaromheen een siliconen coating. De Spectra ${ }^{\mathrm{TM}}$ heeft geen inhibizone en is thans niet impregneerbaar met antibiotica.

\section{Wat zijn de risico's?}

Na protheseplaatsing is de meest gevreesde complicatie een hooggradige infectie door een virulente purulente verwekker. De patiënten die dit treft, zijn ziek en hebben pijn, ze hebben hoge infectieparameters, er treedt necrose op van weefsel rondom een exposure, en/of pusvorming rondom het implantaat. De prothese moet met spoed verwijderd worden. Dit risico ligt in de laatste series rond de 1,4-8,9\% [5-7]. Een laaggradige infectie wordt meestal veroorzaakt door de Staphylococcus epidermidis. Dan is de patiënt niet ziek en zichtbaar exsudaat is helder. Behandeling bestaat uit antibiotica en zo nodig een salvageprocedure $[6,7]$. Bij die procedure wordt de prothese in dezelfde setting vervangen. Tussen explantatie en implantatie worden wond en beide corpora uitgebreid gespoeld met respectievelijk waterstofperoxide, een antiseptisch middel en antibiotica [6]. Het risico op infectie na een salvageprocedure is ongeveer $20 \%[5,6]$.

Vaak wordt in deze situaties, uit kostenoogpunt, een semirigide prothese geplaatst die veel later, als de patiënt dat nog wenst, kan worden vervangen door een driedelig sys- teem. De salvageprocedure voorkomt fibrosevorming die ontstaat na explantatie en voorkomt zo een lastiger re-implantatie en verdere verkorting van de penis. Het risico op infectie is hoger bij patiënten met een dwarslaesie ( $4 \times$ zo hoog), patiënten die steroïden gebruiken, rokers en patiënten die een revisie ondergaan [5]. Bij een revisie is het gebruikelijk een (mini)salvageprocedure te doen, omdat in studies bij $80 \%$ van de revisies een bacteriële biofilm werd gevonden en er dus feitelijk sprake was van een laaggradige infectie [8].

Revisies voor mechanische of cosmetische problemen zijn bij ongeveer $35 \%$ van de implantaties nodig [9]. Een revisie kan bestaan uit het vervangen van het hele systeem, onderdelen van het systeem, maar ook het herplaatsen van onderdelen en/of corrigeren van glansdeformaties of ontsierende huiddelen.

\section{Hoe tevreden is de patiënt met een erectieprothese? En zijn partner?}

Een mooi uitgangspunt voor het antwoord op deze vraag is afkomstig uit twee oude studies van Nederlandse bodem. In 1991 en 2001 beschreef de groep van Meuleman de resultaten van een enquête- en interviewstudie bij respectievelijk 28 en 124 patiënten die vanaf 1985 een hydraulische prothese hadden gehad $[1,9]$. Het bleek dat $40 \%$ respectievelijk $50 \%$ van de mannen tevreden was. De tevredenheid was vooral goed bij mannen met voldoende seksueel repertoire binnen een partnerrelatie, die de prothese meer zagen als een aanvulling op dit repertoire [9].

De ontevredenheid kwam er vooral uit voort dat de penis door het oppompen niet langer werd, waardoor de coïtus bemoeilijkt werd of zelfs helemaal niet lukte (bij 20\%). Andere factoren waren een verminderd gevoel en/of pijn. Bij follow-up gebruikte $31 \%$ van de mannen de prothese niet meer. $15 \%$ van de mannen had hem zelfs nog nooit gebruikt. Desondanks had maar 16-17\% van de mannen spijt van de implantatie. Kennelijk leidt de implantatie van een prothese niet tot een verbetering van de seksuele relatie, maar mogelijk wel tot een verbetering van zelfvertrouwen en zelfwaardering van de man.

Recente internationale studies tonen rond de $85 \%$ tevredenheid [10]. Deze cijfers komen meestal uit hoogvolumecentra, waar mannen over het algemeen eerder worden geïmplanteerd. De corpora zijn dan minder gefibroseerd, waardoor er minder initiële verkorting is, zodat langere cilinders geïmplanteerd kunnen worden [11]. Kanttekening is dat deze studies meestal door de industrie gesponsord werden en de percentages mogelijk dus gekleurd zijn. Bij onderzoek naar de tevredenheid binnen subgroepen lijkt het dat mannen na een radicale prostatectomie (RP) significant minder tevreden zijn. Mogelijk komt het omdat bij mannen 
na een RP hun erecties vrij abrupt verslechteren, en er verlies van ejaculatie optreedt, en ze daarmee een verminderde orgasmebeleving hebben [10]. Ten opzichte van de hydraulische prothese scoort de semirigide prothese minder goed wat betreft tevredenheid [12]. Opvallend is dat een andere studie concludeert dat $74 \%$ van de mannen geen probleem heeft met het stijf blijven van de penis [13].

Bij de studie van Meuleman uit 2001 werden ook gesprekken gevoerd met 44 mannen en hun partner. Van de partners zag $45 \%$ geen verandering en $22 \%$ zelfs een verslechtering in de seksuele relatie na implantatie. Bij slechts $32 \%$ trad verbetering op [9].

Uit een recente studie blijkt dat er een sterke positieve correlatie is met de tevredenheid van de man en de seksuele functie van de vrouw (gemeten met de Female Sexual Index scale) [14]. Het is dus belangrijk de partner bij de counseling te betrekken [15].

Helaas is er nog geen gevalideerde uitkomstmaat beschikbaar voor het meten van de tevredenheid van de behandeling met een erectieprothese. Het meten van tevredenheid is lastig, omdat er zoveel facetten meespelen. Sinds 2014 is er wel een gevalideerde vragenlijst voor het meten van de uitkomst van de erectieprothese op de kwaliteit van leven; de Quality of Life and Sexuality with Penile Prosthesis (QoLSPP) [16]. Bij het construeren en valideren van deze vragenlijst blijkt, net als bij de studie van Meuleman, dat een prothese vooral de eigenwaarde en het zelfvertrouwen van de man verbetert. Het wachten is nog op studies die dit meetinstrument gebruiken. De tevredenheid kan het beste een jaar na implantatie worden gemeten [10]. In het algemeen kan gesteld worden dat de tevredenheid afhankelijk is van het uiteindelijke functionele resultaat en van de verwachting van de patiënt en zijn partner. Is er de verwachting dat bij puur herstel van een mechanische erectie alles beter wordt, dan vallen de resultaten juist tegen [9]. Om de tevredenheid te maximaliseren is het dan ook belangrijk dat zowel de man als de partner in psychoseksueel opzicht wordt begeleid en goede voorlichting en seksuologische counseling krijgen.

\section{Wie komt voor een erectieprothese in aanmerking en wie niet?}

De hydraulische erectieprothese is de meeste succesvolle behandeling voor ED [17]. Desalniettemin maakt de behandeling deel uit van de stepped-carebenadering bij ED [3, 18]. Dat betekent dat een man met ED eerst PDE-5remmers en daarna caverneuze injectietherapie met bijvoorbeeld androskat moet hebben geprobeerd, beide eventueel in combinatie met Muse of een vacuümpomp, alvorens hij in aanmerking komt voor een erectieprothese (tab. 1). De reden is dat behandeling met een erectieprothese duur en
Tabel 1 Indicaties en contra-indicaties voor implantatie van een erectieprothese [3]

indicaties

- therapieresistente erectiele disfunctie: falen van mechanische, medicamenteuze en seksuologische behandeling binnen een partnerrelatie

- peniele kromstand >45 graden bij de ziekte van Peyronie + erectiele disfunctie

- ischemisch priapisme $>72$ uur

- revisie van een erectieprothese

- in het kader van genderchirurgie of reconstructieve chirurgie

- ter ondersteuning van de penis bij gebruik van condoomkatheter (bij neurogene blaas)

contra-indicaties

- body mass index $\geq 35$

- antispermatozoa-antistoffen $>3$

- roken en niet bereid zijn hiermee te stoppen

- niet voldoen aan de Nederlandse Norm Gezond Bewegen

- actieve systemische, cutane of urineweginfecties

- slecht gereguleerde diabetes mellitus

- progressieve maligniteit

definitief is (het erectieweefsel wordt immers opgeofferd). Aan de voorwaarde voor implantatie is expliciet toegevoegd dat er een 'falen is binnen een partnerrelatie', op grond van de bevinding dat tevredenheid van een erectieprothese beter is als de partner actief betrokken wordt bij de behandeling. Een partnerrelatie betekent overigens niet per se een vaste partner. Ook bij mannen met een wens voor een partnerrelatie, waarbij juist het erectieprobleem belemmerend werkt, kan een uitzondering worden gemaakt, mits de man uitgebreid seksueel gecounseld is en zo nodig een second opinion van een collega is gezocht.

Bij twijfel of de ED een organische etiologie heeft of bij twijfel over de erectiele restcapaciteit kan een waking erectile assessment (WEA) aangevraagd worden. Een peniele duplex is minder betrouwbaar gebleken [19]. De WEA is een seksuologisch functieonderzoek, waarbij de veranderingen in de penisomtrek wordt gemeten onder invloed van visuele (erotische film) en/of vibrotactiele stimulatie, waarbij ook allerlei psychologische trucs worden toegepast om iemand af te leiden van remmende gedachten en toeschouwersgedrag [19]. Een functieonderzoek is overigens geen vereiste in de work-up.

Relatief nieuwe indicaties zijn de ziekte van Peyronie met een kromstand van meer dan 45 graden in combinatie met een ED die niet op PDE-5-remmers reageert, en langdurig priapisme (zie ook tab. 1). Het is een toenemend geaccepteerde gedachte dat het corrigeren van een kromstand bij een ED die niet op een PDE-5-remmer reageert, een kunstfout is [18]. Door de kromstandcorrectie zal de erectiefunctie niet verbeteren. Door gebruik van injectietherapie en door de ziekte zelf zal door fibrosevorming een 
Hier staat een advertentie.

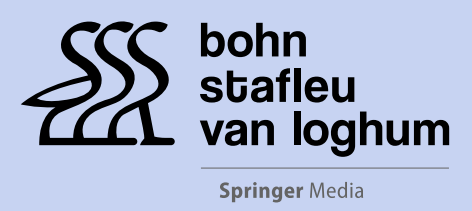

Houten 2018 
Hier staat een advertentie.

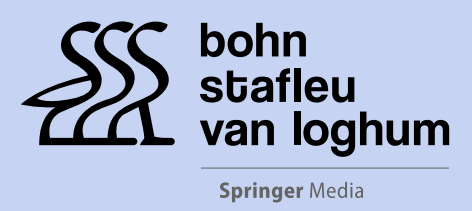

Houten 2018 
Hier staat een advertentie.

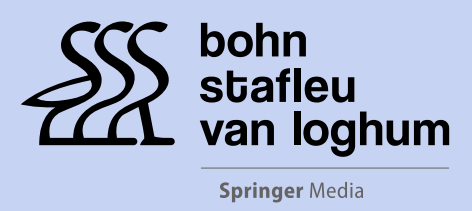

Houten 2018 
Hier staat een advertentie.

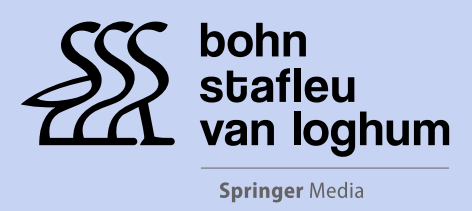

Houten 2018 
implantatie in tweede instantie lastiger worden met kans op onnodige verkorting van de penis en dus een minder tevreden patiënt. Peroperatief kan modificatie van de kromstand plaatsvinden [20]. In een dergelijk geval zal er voor behandeling van de kromstand verwezen moeten worden naar een prothesecentrum.

Bij een (ischemisch) priapisme van meer dan 72 uur zal de natuurlijke erectiefunctie niet meer herstellen. Een prothese is dan de enige oplossing. Als het priapisme operatief gecoupeerd moet worden, kan meteen een prothese geïmplanteerd worden. Zo niet, dan binnen zeven dagen [18, 21]. De reden is ook hier het voorkomen van uitgebreide fibrose van de corpora, met risico op een minder goede uitkomst van implantatie. Meestal wordt eerst een semirigide prothese geïmplanteerd, die later eventueel kan worden vervangen door een hydraulisch systeem.

In de work-up zijn ook de contra-indicaties van belang: bij rokers, mannen die een actieve infectie hebben of morbide adipositas is er een groter risico op complicaties. Ook de bloedsuikerspiegel is van belang; deze moet zo goed mogelijk gereguleerd zijn. Bij een ASA 4, iemand die amper nog beweegt of iemand met een slechte prognose is het de vraag of een erectieprothese zin heeft [3].

\section{Urologische en seksuologische counseling}

Naast de redelijk objectieve indicaties en contra-indicaties is het van groot belang dat de uroloog die de implantatie gaat doen, het vertrouwen heeft dat de preoperatieve verwachtingen overeenkomen met de postoperatieve realiteit. Dit is de uitdaging bij het counselen van de man (en zijn partner) bij de wens voor een erectieprothese. Als de kloof niet te overbruggen lijkt, is het verstandig van implantatie af te zien.

Allereerst is het van belang te praten over de verwachtingen ten aanzien van de penislengte en het feit dat de penis met een prothese niet langer wordt dan zonder. De penis is meestal al verkort door fibrosering en verkort nog wat meer door de operatie zelf. Ook is het van belang te praten over de risico's op infectieuze, mechanische en/of esthetische complicaties. Tot slot is het belangrijk de patiënt goed voor te bereiden op de operatie en het postoperatieve herstel, dat gepaard gaat met pijn, zwelling, en soms gevoelsstoornissen, en de duur van het herstel. Om tot een juiste beslissing te komen, is ook de mening van een seksuoloog ontzettend belangrijk. Al in de beginjaren van Udo Jonas werden patiënt en partner voor de implantatie uitgebreid seksueel gecounseld [22]. Het belang van seksuologische counseling voor het krijgen van een tevreden patiënt is logisch en aangetoond [14, 15]. Onderwerpen die besproken moeten worden zijn: de achtergrond waartegen de wens om een prothese te laten plaatsen zich afspeelt, de motivatie voor een prothese, de medische, psychosociale en sociaal-relationele factoren die een rol spelen, mogelijke alternatieve behandelingen, de verwachtingen en of deze realistisch zijn en, tot slot, het omgaan met tegenslag bij een mechanische of esthetische onvolkomenheid of, in het ergste geval, infectie waarbij de prothese verwijderd moet worden [23].

\section{Conclusie en aanbevelingen}

Het is duidelijk dat de erectieprothese na ruim 40 jaar ook in Nederland een belangrijke plaats heeft ingenomen in de behandeling van ED. Door regionalisatie, registratie van uitkomsten, het up-to-date houden van het NVUstandpunt over de erectieprothese en door intensieve samenwerking tussen implanteurs onderling en implanteurs en seksuologen, kunnen de resultaten van deze behandeling voor de man en zijn partner in de toekomst blijvend verbeteren [3]. Dit is waarom we het uiteindelijk doen. Niet in prothesecentra werkzame urologen kunnen bij een man met ED starten met PDE-5-remmers of intracaverneuze injectietherapie, eventueel aangevuld met Muse of een ring/vacuümpomp [24]. Bij een man na een (prostaat)kankerbehandeling bij voorkeur binnen een seksueel revalidatieprogramma $[25,26]$. Bij falen van de ED-behandeling, ondanks goede begeleiding, is het echter van belang niet te lang te wachten met het verwijzen van deze patiënt naar een prothesecentrum.

Open Access This article is distributed under the terms of the Creative Commons Attribution 4.0 International License (http:// creativecommons.org/licenses/by/4.0/), which permits unrestricted use, distribution, and reproduction in any medium, provided you give appropriate credit to the original author(s) and the source, provide a link to the Creative Commons license, and indicate if changes were made.

\section{Literatuur}

1. Tuyn EA, Meuleman EJH, Sabbe BGC, Bierkens PB. Ervaringen van patienten met de hydraulische erectieprothese. 1991. pag. 518-22.

2. Rodriguez KM, Pastuszak AW. A history of penile implants. Transl Androl Urol. 2017;6(S5):S851-S7.

3. Glas A, Kropman R, Beck J, Vries P de, D'Hauwers K, Dohle G, et al. NVU standpunt. Indicatie en kwaliteitsvoorwaarden erectieprothese. 2016.

4. Stember DS, Garber BB, Perito PE. Outcomes of abdominal wall reservoir placement in inflatable penile prosthesis implantation: a safe and efficacious alternative to the space of retzius. J Sex Med. 2014;11(2):605-12.

5. Narang GL, Figler BD, Coward RM. Preoperative counseling and expectation management for inflatable penile prosthesis implantation. Transl Androl Urol. 2017;6(S5):S869-80.

6. Mulcahy JJ, Kramer A, Brant WO, Parker JL, Perito PE, Myers $\mathrm{JB}$, et al. Current management of penile implant infections, device 
reliability, and optimizing cosmetic outcome. Curr Urol Rep. 2014; Jun;15(6):413.

7. Gross MS, Phillips EA, Carrasquillo RJ, Thornton A, Greenfield JM, Levine LA, et al. Multicenter investigation of the micro-organisms involved in penile prosthesis infection: an analysis of the efficacy of the AUA and EAU guidelines for penile prosthesis prophylaxis. J Sex Med. 2017;14(3):455-63.

8. Faller M, Kohler T. The status of biofilms in penile implants. Microorganisms. 2017;5(2):19.

9. Meuleman EJH, Deunk I, Schreuders Bias C, Rabsztyn PRI. Teleurstellende langetermijnervaringen van patiënten met een erectieprothese. Ned Tijdschr Geneeskd. 2001;145(16):1999-2002.

10. Akakpo W, Pineda MA, Burnett AL. Critical analysis of satisfaction assessment after penile prosthesis surgery. Sex Med Rev. 2017;5(2):244-51.

11. Henry GD, Kansal NS, Callaway M, Grigsby T, Henderson J, Noble J, et al. Centers of excellence concept and penile prostheses: an outcome analysis. J Urol. 2009;181(3):1264-8.

12. Bozkurt IH, Arslan B, Yonguç T, Kozacioglu Z, Degirmenci T, Gunlusoy B, et al. Patient and partner outcome of inflatable and semi-rigid penile prosthesis in a single institution. Int Braz J Urol. 2015;41(3):535-41.

13. Tegelaar RJ, Lyclema A, Nijeholt AAB, Kropman RF. Ervaringen van patienten met de semi-rigide Jonas prothese. Ned Tijdschr Geneeskd. 1991;135(12):514-8.

14. Moskovic DJ, Gittens P, Avila D Jr., Chandrashekar A, Khera M, Lipshultz LI. Favorable female sexual function is associated with patient satisfaction after inflatable penile prosthesis implantation. J Sex Med. 2011;8(7):1996-2001.

15. Pisano F, Falcone M, Abbona A, Oderda M, Soria F, Peraldo F, et al. The importance of psychosexual counselling in the re-establishment of organic and erotic functions after penile prosthesis implantation. Int J Impot Res. 2015;27(5):197-200.

16. Caraceni E, Utizi L. A questionnaire for the evaluation of quality of life after penile prosthesis implant: quality of life and sexuality with penile prosthesis (QoLSPP): To what extent does the implant affect the patient's life? J Sex Med. 2014;11(4):1005-12.
17. Kucuk EV, Tahra A, Bindayi A, Onol FF. Erectile dysfunction patients are more satisfied with penile prosthesis implantation compared with tadalafil and intracavernosal injection treatments. Andrology. 2016;4(5):952-6.

18. Hatzimouratidis K, Giuliano F, Moncada I, Muneer A, Salonia A, Verze P. EUA guideline on erectile dysfunction, premature ejaculation, penile curvature and priapism. Arnhem: EAU; 2016. pag. $1-86$.

19. Janssen E, Everaerd W, Van Lunsen RHW, Oerlemans S. Validation of a psychophysiological waking erectile assessment (WEA) for the diagnosis of male erectile disorder. Urology. 1994;43(5):686-95.

20. Berookhim BM, Karpman E, Carrion R. Adjuvant maneuvers for residual curvature correction during penile prosthesis implantation in men with Peyronie's disease. J Sex Med. 2015;12(suppl 7):449-54.

21. Reddy AG, Alzweri LM, Gabrielson AT, Leinwand G, Hellstrom WJG. Role of penile prosthesis in priapism: a review. World J Mens Health. 2018;36(1):4.

22. Jonas U, Hengeveld MW, Bergh H, Bergh J. Jonas prothese. Leiden: Harry Bacon Club, Nederlandse Vereniging van Stoma-patienten; 1984. pag. 1-20.

23. Kruijver E, Beck J. Erectieprothese. Seksuologische screening (folder); 2016.

24. van Driel MF. Erectiele disfunctie in urologisch perspectief. Ned Tijdschr Geneeskd. 2018;22:1-7.

25. Reisman Y, Gianotten W. De stand van zaken over seksualiteit na behandeling van prostaatkanker: Is herstel van erectiele functie voldoende. Tijdschr Seksuol. 2017;41(4):148-53.

26. Grondhuis Palacios LA, Krouwel EM, Oudsten BL den, Ouden MEM den, Kloens GJ, Duijn G van, et al. Seksuele disfunctie en relatieproblemen na prostaatkankerbehandeling: De gewenste zorg vanuit het oogpunt van patiënt en partner. Tijdschr Urol. 2018;8(1):2-9.

\section{drs. Brechje Ronkes uroloog}

dr. Afina S. Glas uroloog, medisch seksuoloog FECSM 